\title{
Papio hamadryas hamadryas
}

National Cancer Institute

\section{Source}

National Cancer Institute. Papio hamadryas hamadryas. NCI Thesaurus. Code C161027.

The baboon sub-species, Papio hamadryas hamadryas. 